\title{
Using Randomly Amplified Polymorphic DNA (RAPD) Markers to Identify Annona Cultivars
}

\author{
C.M. Ronning ${ }^{1}$ and R.J. Schnell \\ U.S. Dept. of Agriculture, National Clonal Germ Plasm Repository, 13601 Old Cutler Road, Miami, FL 33158
}

S. Gazit

Faculty of Agriculture, The Hebrew University of Jerusalem, P.O. Box 12, Rehovot 76100, Israel

Additional index words. Annona squamosa, A. cherimola, atemoya, cultivar identification

\begin{abstract}
The native American genus Annona contains many species that are cultivated for their edible fruit, including the custard apple (A. reticuluta L.), soursop (A. muricata L.), cherimoya (A. cherimola L.), sugar apple (A. squamosa L.), and interspecific hybrids, the atemoyas. RAPD analysis of $A$. cherimola. 'Campa' and 'Jete,' A. squamosa 'Lessard,' and the atemoyas 'Ubranitzki,' 'Malali,' and 'Kaspi' resulted in very distinctive patterns, indicating that RAPD markers, may be an efficient method of fingerprinting genotypes within and between Annona species. All 15 primers used generated repeatable, polymorphic patterns. An $\mathbf{F}_{1}$ population of 'Jete' $x$ 'Lessard' was analyzed to determine the inheritance of the RAPD banding patterns. Fifty-two polymorphic loci were identified, which segregated in an expected Mendelian fashion.
\end{abstract}

Annona contains more than 50 species and interspecific hybrids, many of which are cultivated in tropical and subtropical America for their edible fruit. The genus has been divided into five groups and 14 sections based on morphological characters (Safford, 1914). Cherimoya (A. cherimola) originated in the highlands of Ecuador and Peru (Zeven and Zhukovsky, 1975). Cultivars of this early-maturing species have a superior flavor and are cold-tolerant 'Jete' and 'Campa' are two Spanish cultivars representative of this species. Sugar apple (A. squamosa) is native to the Central American lowlands and the West Indies, and is suited to tropical climates. The fruit is considered inferior to cherimoya, but is exceptionally high in calcium, phosphorous, and iron (Sturrock, 1959). This species is drought tolerant and grows well in alkaline soils. $A$. squamosa is less variable than the other Annona species (Sturrock, 1959). 'Lessard' is a representative commercially grown cultivar. Other species, such as A. muricata (soursop) and A. reticulata (custard apple; Bullock's heart) vary widely in fruit quality, flavor, habitat, and insect susceptibility.

$A$. cherimola and $A$. squamosa are closely related, both belonging to the section Atta (Safford, 1914). The diploid chromosome number for A. squamosa and A. cherimola is probably 14, although $2 n=16$ has also been reported (Darlington and Wylie, 1956). Both species are protogynous; their flowering patterns favor the formation of hybrids over self-pollination (Gazit and Eisenstein, 1985). Cross-pollination occurs via nitidulid fruit beetles (Gazit et al., 1982). The first artificial interspecific hybridizations were made in Florida in 1908, by P.J. Wester and E. Simmonds (Sanewski, 1988). Wester proposed the name "atemoya" for these hybrids. The atemoyas vary considerably, combining characteristics of both parents. Like A. cherimola, the atemoyas produce fineflavored fruit on a large, long-lived tree; like A. squamosa, atemoyas fruit consistently in a warm climate. Several cultivars have been selected and vegetatively propagated, including 'Gefner,' 'Ubranitzki,' 'Kaspi,' and 'Malali.'

Annona is quite popular in tropical and subtropical America. Although grown in California and southern Florida, the fruit has

Received for publication 10 Nov. 1994. Accepted forpublication 17 Apr. 1995. We thank Paul Madeira for his excellent technical assistance. The cost of publishing this paper was defrayed in part by the payment of page charges. Under postal regulations, this paper therefore must be hereby marked advertisement solely to indicate this fact.

${ }^{1}$ To whom all reprint requests should be addressed. not gained wide acceptance in the United States. The parentage of most cultivars is unknown. The wide range of phenotypic variation existing between species suggests that an organized breeding effort would be highly successful. Efforts to improve rootstocks, hardiness, productivity, fruit quality, and postharvest and shipping qualities could be very rewarding, as evidenced by the performance of the atemoya under the subtropical, low elevations of southern Florida (Sturrock, 1959).

Genetic variation between cherimoya cultivars has been studied using isozyme markers (Ellstrand and Lee, 1987; Lee and Ellstrand, 1987; Pascual et al., 1993); however, isozyme analysis is limited by the relatively small number of loci. Recently, RAPD, a polymerase-chain reaction technology using 10-mer primers, has been introduced (Welsh and McClelland, 1990; Williams et al., 1990). RAPD markers offer the potential of generating large numbers of markers representing a random sample of the genome, thereby presenting an advantage over isozyme markers. Our objective was to estimate variation between A. cherimola, A. squamosa, and interspecific atemoya hybrids using RAPD markers. Also, we determined the inheritance of these markers within an F, family of the interspecific cross A. squamosa 'Jete' x A. cherimola 'Lessard' to ascertain the efficacy of such markers for genetic analysis of Annona.

\section{Materials and Methods}

Plant materials. Annona cherimola 'Jete' and 'Campa,' A. squamosa 'Lessard,' and the atemoya 'Kaspi' are located at the Experimental Farm of the Faculty of Agriculture, Hebrew University, Rehovot, Israel. The atemoyas 'Ubranitzki' and 'Malali' were collected from the Warburg Acclimatization Garden in Rehovot. The family used in this study, located at the U.S. Dept. of Agriculture National Clonal Germ Plasm Repository in Miami, includes $38 \mathrm{~F}_{1}$ individuals from the interspecific cross 'Jete' $\mathrm{x}$ 'Lessard.'

DNA extraction. Genomic DNA was extracted according to the protocol of Dellaporta et al. (1983) with modifications. Young leaves were ground in a mortar and pestle with $10 \mathrm{ml} \cdot \mathrm{g}^{-1}$ fresh weight (FW) extraction buffer (100 mM Tris-HCl, pH 8.0; $250 \mathrm{~mm}$ $\mathrm{NaCl} ; 25 \mathrm{~mm}$ ethylenediaminetetraacetic acid (EDTA), $0.1 \%$ (v/v) 2-mercaptoethanol; $0.1 \mathrm{M}$ diethyldithiocarbamic acid (DEDTC); $2 \%(\mathrm{w} / \mathrm{v})$ polyvinylpolypyrrolidone (PVPP)). The homogenate was filtered through four layers of cheesecloth. Sodium dodecyl 
Table 1., RAPD Primers used to analyze genetic variation between Annona cherimola 'Jete' and 'Campa,' A. squamosa 'Lessard,' and the atemoyas 'Ubranitzki,' 'Malali,' and 'Kaspi.' Percent polymorphism reflects the number of total bands from each primer that distinguish at least one cultivar.

\begin{tabular}{lccc}
\hline \hline & No. & $\begin{array}{c}\text { No. } \\
\text { polymorphic } \\
\text { bands }\end{array}$ & $\begin{array}{c}\text { Percent } \\
\text { polymorphism }\end{array}$ \\
\hline Primer & bands & 6 & 100 \\
A14 & 6 & 3 & 100 \\
A16 & 3 & 3 & 100 \\
A17 & 3 & 2 & 100 \\
A18 & 2 & 12 & 100 \\
A20 & 12 & 5 & 100 \\
B11 & 5 & 5 & 100 \\
B18 & 5 & 6 & 100 \\
C11 & 6 & 9 & 90 \\
C19 & 10 & 3 & 100 \\
D8 & 3 & 7 & 100 \\
D11 & 7 & 14 & 93 \\
E3 & 15 & 1 & 25 \\
E7 & 4 & 5 & 100 \\
H20 & 5 & 5 & 83 \\
Total & 6 & 86 & 93.5 \\
& 92 & &
\end{tabular}

sulfate (SDS) was added to a final concentration of $1.25 \%$, and the solution was incubated at $65 \mathrm{C}$ for $10 \mathrm{~min}$. Potassium acetate was added to a final concentration of $1.2 \mathrm{M}$. The suspension was allowed to stand for $20 \mathrm{~min}$ in an ice water bath, then samples were centrifuged at $25,000 \times \mathrm{g}, 4 \mathrm{C}$, for $20 \mathrm{~min}$. After filtration through two layers of Miracloth, the nucleic acids were precipitated from the supernatant with cold isopropanol. Resuspended pellets were treated with RNase A, and DNA concentrations were determined spectrophotometrically.

Amplification. Genomic DNA was amplified using 15 different RAPD primers (Operon Technologies; Alameda, Calif.) (Table 1). The reaction included $50 \mathrm{~mm} \mathrm{KCl}, 10 \mathrm{~mm}$ Tris- $\mathrm{HCl}(\mathrm{pH} 9.0), 0.1$ $\%(\mathrm{v} / \mathrm{v})$ Triton X-100,2.5 mM MgC1 ${ }_{2}, 100 \mu \mathrm{m}$ each dATP, dCTP, dTTP, and dGTP, $0.02 \mathrm{U} / \mu \mathrm{l}$ Taq DNA polymerase (Promega; Madison, Wis.), $0.3 \mu \mathrm{M}$ primer, and $0.4 \mathrm{ng} \cdot \mu \mathrm{l}^{-1}$ genomic DNA, in a final volume of $25 \mu \mathrm{l}$. Reactions were either amplified immediately or stored at 20C for up to 1 week. Amplifications were performed in a DNA thermal cycler (model 480; Perkin Elmer, Norwalk, Conn.) preheated to 94C. Cycling parameters were 45 cycles of 94C, $1 \mathrm{~min}$; 37C, $1 \mathrm{~min}$; and 72C, 2 min. PCR products were separated by electrophoresis on a $1.4 \%$ agarose gel in $0.5 \times$ TBE buffer ( $0.045 \mathrm{M}$ Tris-borate, $0.001 \mathrm{M}$ EDTA), and visualized by ethidium bromide staining.

Analysis. Each individual was amplified at least two times; reproducible, polymorphic bands were scored as 1 (band present) or 0 (band absent). Percent band sharing between pairs of cultivars was calculated as the number of shared bands divided by the total number of bands.

Expected segregation ratios in the $\mathrm{F}$, were determined from the parental phenotypes of those loci for which expected segregation ratios could be unambiguously assigned (Table 2). Chi-square analysis was then performed on these loci to determine goodnessof-fit of observed to expected ratios for the $\mathrm{F}_{1}$ full-sib family. Proportions of homozygotes and heterozygotes, as well as allele frequencies of 'Jete' and 'Lessard' were calculated from those loci from which parental genotypes could be definitely assigned, again according to Table 2 .
A18

C11

$\mathrm{H} 2 \mathrm{O}$

\section{$123456123456123456 \quad$ bp}
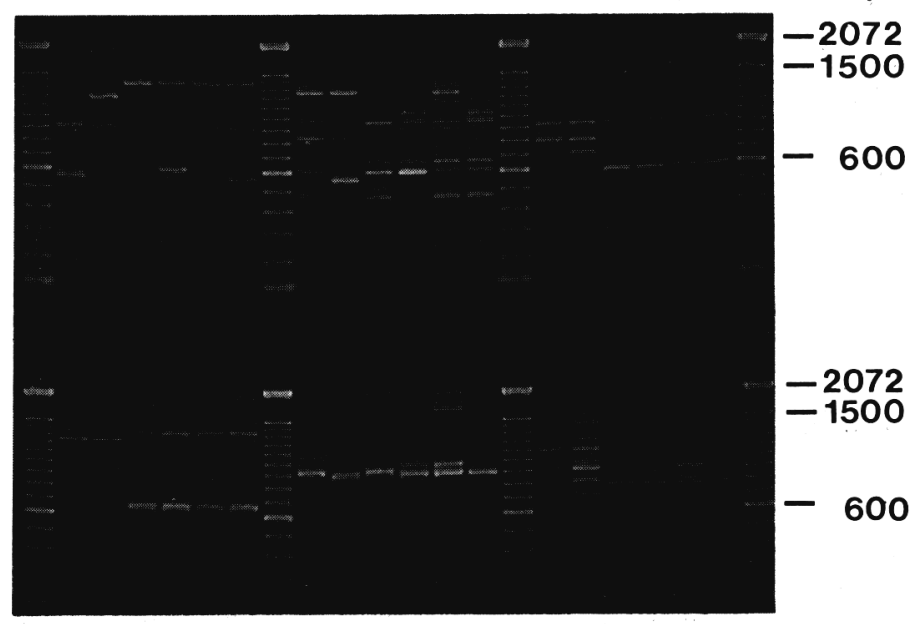

A20

B11

D8

Fig. 1. Phenotypic variation in RAPD patterns between six Annona cultivars of two species and interspecific hybrids, amplified with RAPD primers A18, C11, H20, A20, B11, and D8. Lane 1: A. cherimola 'Jete'; lane 2: A. cherimola 'Campa'; lane 3: A. squamosa 'Lessard'; lane 4: atemoya 'Ubranitzki'; lane 5: atemoya 'Kaspi'; lane 6: atemoya 'Malali'. Size markers are 100 bp ladder (Gibco BRL, Gaithersburg, Md.). PCR products were electrophoresed on $1.4 \%$ agarose in $0.5 \times$ TBE and stained with EtBr.

\section{Results}

While more than 30 Operon primers were used initially, 15 gave optimal results, generating a total of 107 bands in A. cherimola 'Jete' and 'Campa', A. squamosa 'Lessard', and the atemoyas 'Ubranitzki', 'Malali', and 'Kaspi' (Fig. 1). Fifteen of these bands, all but two of which were light in intensity, were unrepeatable; therefore a total of 92 bands, or loci, were scored. All 15 primers produced at least one variable locus in all cultivars; all but four primers were $100 \%$ polymorphic (Table 2 ).

Percent bands shared between pairwise combinations of species and cultivars are shown in Table 3. Band sharing between cultivars showed that a high identity $(83.7 \%)$ exists between $A$. cherimola 'Jete' and 'Campa'. Good identity was also found within the atemoya cultivars $(65.2 \%$ to $79.3 \%)$ and between $A$. squamosa 'Lessard' and the atemoyas (67.4\% to $71.7 \%)$. The least amount of genetic identity was found between $A$. cherimola cultivars and A. squamosa (26.1\% and $27.2 \%)$. Identity between the two A. cherimola cultivars and the three atemoyas was average $(34.8 \%$ to $41.3 \%)$.

Table 2. Scheme used to determine expected segregation ratios the $F$ progeny of Annona cherimola 'Jete' x A. squamosa 'Lessard'. 1 = band present; $0=$ band absent.

\begin{tabular}{lcc}
\hline \hline \multicolumn{2}{c}{$\begin{array}{c}\text { Parental phenotypes } \\
\text { (genotypes) }\end{array}$} & \\
\hline Jete & Lessard & Expected segregation in $\mathrm{F}_{1}$ \\
\hline $1(+/+)$ & $1(+/+)$ & All 1 \\
$1(+/+)$ & $1(+/-)$ & All 1 \\
$1(+/-)$ & $1(+/+)$ & All 1 \\
$1(+/-)$ & $1(+/-)$ & $3: 1$ \\
$1(+/+)$ & $0(-/-)$ & All 1 \\
$1(+/-)$ & $0(-/-)$ & $1: 1$ \\
$0(-/-)$ & $1(+/+)$ & All 1 \\
$0(-/-)$ & $1(+/-)$ & $1: 1$ \\
\hline
\end{tabular}


Table 3. Percent bands shared between pairwise combinations of Annona cherimola 'Jete' and 'Campa', A. squamosa 'Lessard', andtheatemoyas 'Ubranitzki' , 'Malali' , and 'Kaspi'

\begin{tabular}{lccccc}
\hline & Jete & Campa & Lessard & Ubranitzki & Malali \\
\hline Campa & 83.7 & & & & \\
Lessard & 27.2 & 26.1 & & & \\
Ubranitzki & 35.9 & 39.1 & 71.7 & & \\
Malali & 34.8 & 35.9 & 70.6 & 75.0 & \\
Kaspi & 40.2 & 41.3 & 67.4 & 65.2 & 79.3 \\
& & & & & \\
\hline
\end{tabular}

Table 4. Number of RAPD loci identified in the $\mathrm{F}_{1}$ progeny from Annona cherimola 'Jete' x A. squamosa 'Lessard', amplified with 15 Operon primers. Expectations are based on parental phenotypes.

\begin{tabular}{lc}
\hline & No. loci \\
\hline Segregating in $\mathrm{F}_{1}$ as expected & 22 \\
Present in 1 parent only, and in all progeny & 30 \\
\multicolumn{1}{c}{ Regular (Mendelian) segregation } & 52 \\
& --- \\
Irregular segregation & 25 \\
Total polymorphic loci & --- \\
Monomorphic loci & 76 \\
Total loci & 6 \\
& 83 \\
\hline
\end{tabular}

Table 5. Segregation of 22 RAPD-generated polymorphic bands in the $\mathrm{F}_{1}$ progeny of the interspecific cross Annona cherimola 'Jete' x A. squamosa 'Lessard' $\left(x_{1,05}^{2}=3.841\right)$.

\begin{tabular}{|c|c|c|c|c|c|}
\hline \multirow[b]{2}{*}{ Locus } & \multirow[b]{2}{*}{ Jete } & \multirow[b]{2}{*}{ Lessard } & \multicolumn{2}{|c|}{$F_{1}$ ratios $^{x}$} & \multirow[b]{2}{*}{$x^{2}$} \\
\hline & & & Observed & Expected & \\
\hline A3-1050 & 0 & 1 & $20: 18$ & $19: 19$ & 0.105 \\
\hline A3-1080 & 1 & 0 & $18: 20$ & $19: 19$ & 0.105 \\
\hline A3-1200 & 1 & 0 & $21: 17$ & $19: 19$ & 0.421 \\
\hline A16-1450 & 1 & 0 & $23: 15$ & $19: 19$ & 1.684 \\
\hline A17-950 & 0 & 1 & $13: 25$ & $19: 19$ & 3.789 \\
\hline A17-1100 & 1 & 0 & $22: 16$ & $19: 19$ & 0.947 \\
\hline A18-700 & 1 & 1 & $31: 5$ & $27: 9$ & 2.370 \\
\hline A18-920 & 1 & 0 & $14: 24$ & $19: 19$ & 2.632 \\
\hline C11-490 & 1 & 0 & $15: 23$ & $19: 19$ & 1.684 \\
\hline C11-670 & 0 & 1 & $23: 15$ & $19: 19$ & 2.189 \\
\hline C11-840 & 1 & 0 & $21: 17$ & $19: 19$ & 0.421 \\
\hline C11-910 & 0 & 1 & $23: 15$ & $19: 19$ & 1.684 \\
\hline C11-1270 & 1 & 0 & $20: 18$ & $19: 19$ & 0.105 \\
\hline D8-1450 & 1 & 0 & $16: 22$ & $19: 19$ & 0.947 \\
\hline D11-480 & 1 & 0 & $20: 18$ & $19: 19$ & 0.243 \\
\hline D11-1650 & 1 & 0 & $14: 24$ & $19: 19$ & 2.632 \\
\hline E3-480 & 1 & 0 & $16: 22$ & $19: 19$ & 0.974 \\
\hline E7-690 & 1 & 0 & $25: 13$ & $19: 19$ & 3.789 \\
\hline E7-700 & 0 & 1 & $22: 16$ & $19: 19$ & 0.947 \\
\hline E7-750 & 0 & 1 & $14: 24$ & $19: 19$ & 2.632 \\
\hline E7-760 & 1 & 0 & $24: 14$ & $19: 19$ & 2.632 \\
\hline E7-1050 & 1 & 0 & $15: 23$ & $19: 19$ & 1.684 \\
\hline
\end{tabular}

In addition, 30 loci were observed which were present in one parent only and in all of the $F_{1}$ progeny, as expected.

Eighty-three repeatable loci were identified in the $F_{1}$ progeny, of which six were monomorphic (Table 4). Fifty-two of the polymorphic loci $(67.5 \%)$ segregated as expected in the $\mathrm{F}$, as determined by chi-square goodness-of-fit tests (Tables 4 and 5; Fig. 2). Twenty-five loci, or $32.5 \%$, had irregularratios. Of 52 loci for which parental genotypes could be ascertained, 'Jete' was $30.8 \%$ heterozygous, while 'Lessard' was $13.5 \%$ heterozygous (Table 6). The proportion of "positive" (present) and "negative" (absent) alleles was about $40 \%$ and $60 \%$, for 'Jete' and 'Lessard,' respectively.

\section{Discussion}

Pascual et al. (1993) distinguished all but two of seven Spanish cherimoya cultivars with 13 isozyme loci; 10 of these loci were identical between 'Jete' and 'Campa.' Our band-sharing results also show a high homology between 'Jete' and 'Campa,' the A. cherimola cultivars (Table 3 ). Since a single RAPD primer may generate several loci (ranging from 2-15 bands in this study), 10 of the fifteen primers, used individually, could be used to distinguish these two closely related cultivars.

For five loci, ratios of $37: 1$ or $36: 2$ were observed, while no segregation (38:0) was expected. These were determined to be close enough to expected for inclusion into the normally segregating group. It is possible that two or more co-migrating loci exist, which would alter expected ratios as demonstrated in cacao (Ronning et al., 1995). Since the sample size of 38 is too small to test this hypothesis, it is assumed that structural, or nongenetic changes at these sites prevented amplification.

Due to the flowering cycles and patterns of $A$. cherimola and $A$, squamosa, spontaneous hybrids will form naturally and inevitably when they are planted in close proximity (Gazit and Eisenstein, 1985). However, the ecological and climatic requirements of the two species are so different as to form a geographical barrier between them in nature. Indeed, A. squamosa 'Lessard' shared only one-fourth of the bands with either A. cherimola cultivar (Table 3).

Although RAPD markers are dominantly inherited, expected segregation ratios in an $\mathrm{F}_{1}$ can be inferred, in some cases, from parental phenotypes. This approach has been useful in studying conifers (Carlson et al., 1991) and cacao (Ronning et al., 1995), perennial species with long generations times in which obtaining segregating $\mathrm{F}_{2}$ progeny from inbred parents is difficult or impossible. As shown in Table 2, expected segregation ratios in an $\mathrm{F}$, can be unambiguously determined from parental phenotypes in all but three cases. For our data, six loci were monomorphic; parental genotypes and hence progeny ratios could not be definitively assigned. Fifty-two loci, however, exhibited standard Mendelian segregation ratios that were used both to determine expected $F_{1}$ ratios and to estimate heterozygosity of the two parents.

When the RAPD genotypes of the parents are extrapolated from the observed segregation ratios in the F,, it was found that 'Jete' is $69.2 \%$ homozygous for these 52 RAPD loci, and 'Lessard' is $86.5 \%$ homozygous, even though allele frequencies between the two cultivars do not differ (Table 6). These results are to be expected; $A$. squamosa cultivars are often propagated by seeds, since they reproduce true to type (Gazit and Eisenstein, 1985). Since the atemoyas are the progeny of $A$. cherimola $\times$ A. squamosa hybridizations, it is interesting to note that the identity between 'Lessard' and the atemoyas is much higher than that between A. cherimola and the atemoyas (averaging $69.9 \%$ and $37.9 \%$, respectively). The presence of higher amounts of $A$. squamosa 'Lessard' in the genetic background of the atemoyas may be the result of backcrossing to $A$. squamosa. It is also possible that the two A. cherimola cultivars analyzed in this study were only distantly related to the parents of these atemoya cultivars. Only nine out of 92 bands were unique to the atemoyas. Very few of the 92 bands were shared only between an $A$. cherimola cultivar and at least one atemoya cultivar: 3 bands between 
1

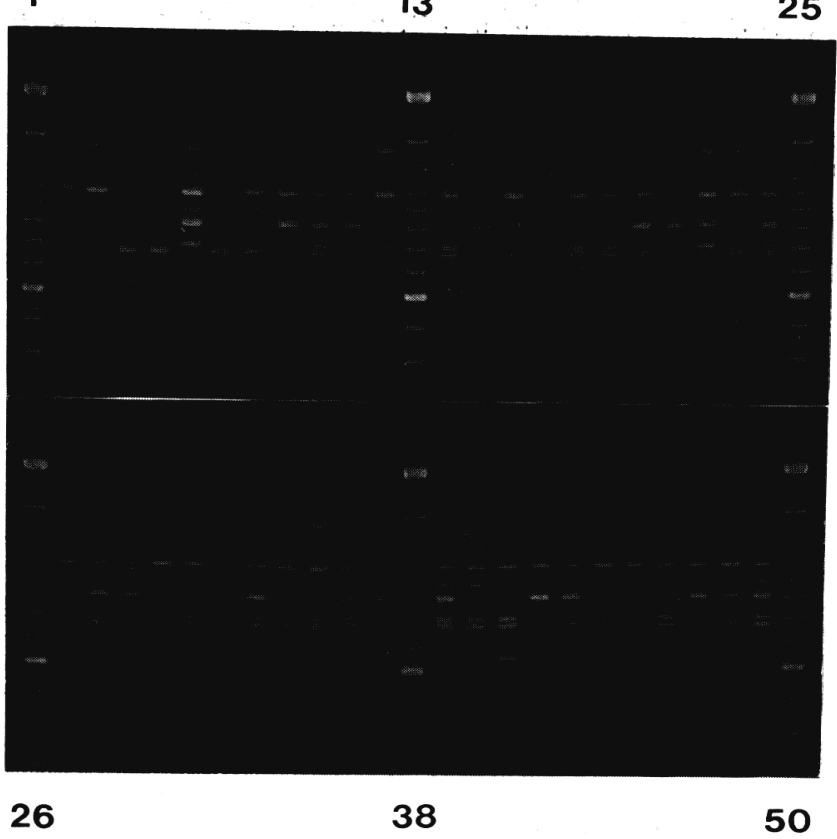

1

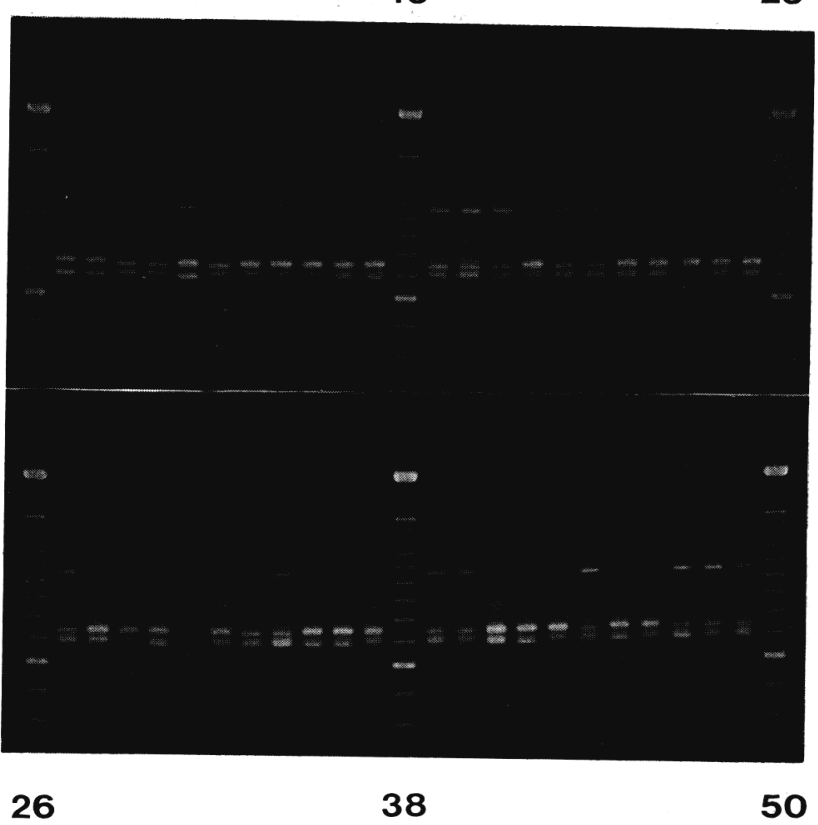

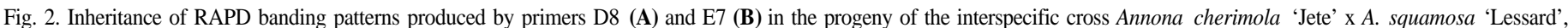
and in two selfed progeny of 'Jete' and 'Lessard.' PCR products were separated on 1.4\% agarose in 5x TBE, and stained with EtBr. Lanes 1, 13, 25, 26, 38, and 50: 100 bp ladder; lanes 2 and 3: 'Jete' selfs; lanes 4 and 5: 'Lessard' selfs; lane 6: 'Jete;' lane 7: 'Lessard;' lanes 8-12, 14-24, 27-37, and 39-49: F, progeny.

Table 6. Proportion of heterozygotes and homozygotes, and allele frequencies, in Annona cherimola 'Jete' and A. squamosa 'Lessard', as calculated from 52 polymorphic RAPD loci. 1 = allele present; $0=$ allele absent.

\begin{tabular}{lcc}
\hline \hline & Jete & Lessard \\
Percent homozygous & 69.2 & 86.5 \\
Percent heterozygous & 30.8 & 13.5 \\
Percent (1) alleles & 40.4 & 39.4 \\
Percent (0) alleles & 59.6 & 60.6 \\
\hline
\end{tabular}

'Campa' and the atemoyas, and 2 between the atemoyas and 'Jete'. However, 25 bands were found to be unique to 'Lessard' and at least one of the atemoya cultivars.

Using RAPD markers, it should be possible to discern these relationships and determine likely parentage. This first work with Annona indicates that RAPDs will be a useful tool in identifying Annona cultivars, and may be valuable for genetic and breeding studies as well.

\section{Literature Cited}

Carlson, J.E., L.K. Tulsieram, J.C. Glaubitz, V.W.K. Luk, C. Kauffeldt, and R. Rutledge. 1991. Segregation of random amplified DNA markers in F, progeny of conifers. Theor. Appl. Genet. 83:194-200.

Darlington, C.D. and A.P. Wylie. 1956. Chromosome atlas of flowering plants. Macmillan, New York.

Dellaporta, S.L., J. Wood, and J.B. Hicks. 1983. A plant DNA minipreparation: version II. Plant Mol. Biol. Rpt. 1: 19-21.
Ellstrand, N.C. and J.M. Lee. 1987. Cultivar identification of cherimoya (Annona cherimola Mill.) using isozyme markers. Sci. Hort. 32:25-31. Gazit, S. and D. Eisenstein. 1985. Floral biology of Annona squamosa and Annona cherimola in relation to the spontaneous appearance of atemoya in Israel. Proc. Trop. Region Amer. Soc. Hort. Sci. 32:66-67.

Gazit, S., I. Galon, and H. Podoler. 1982. The role of Nitidulid beetles in natural pollination of Annona in Israel. J. Amer. Soc. Hort Sci. 107:849-852.

Lee, J.M. and N.C. Ellstrand. 1987. Inheritance and linkage of isozymes in the cherimoya. J. Hered. 78:383-387.

Pascual, L., F. Perfectti, M. Gutierrez, and A.M. Vargas. 1993. Characterizing isozymes of Spanish cherimoya cultivars. HortScience 28:845847.

Ronning, C.M., R.J. Schnell, and D.N. Kuhn. 1995. Inheritance of random amplified polymorphic DNA markers in Theobroma cacao L. J. Amer. Soc. Hort. Sci. 120:681-686.

Safford, W.E. 19 14. Classification of the genus Annona with descriptions of new and imperfectly known species. Contrib. U.S. Natl. Herb., vol. 18, part 1. Govt. Printing Office, Washington, D.C.

Sanewski, G.M. 1988. Growing custard apples. Queensland Dept. of Primary Ind. Info. Ser., Brisbane, Australia.

Sturrock, D. 1959. Fruits for southern Florida. Southeastern Printing Co., Stuart, Fla.

Welsh, J. and M. McClelland. 1990. Fingerprinting genomes using PCR with arbitrary primers. Nucleic Acids Res. 18:7213-7218.

Williams, J.G.K., A.R. Kubelik, K.J. Livak, J.A. Rafalski, and S.V. Tingey. 1990. DNA polymorphisms amplified by arbitrary primers are useful as genetic markers. Nucleic Acids Res, 18:6531-6535.

Zeven, A.C. and P.M. Zhukovsky. 1975. Dictionary of cultivated plants and their centres of diversity. Ctr. Agr. Publ. Documentation, Wageningen. 